\title{
The philosophical foundations of personal human self-determination in the technogenic civilization
}

\author{
Tatyana Torubarova ${ }^{1, *}$, Olga Dyachenko ${ }^{1}$ \\ ${ }^{1}$ Kursk State University, Kursk region, Russia
}

\begin{abstract}
The article considers the problem of human self-identification in the modern world. The relevance of the study is due to the process of human self-alienation, the loss of the person's rootedness in his own foundational content stemming from the human nature itself. The specificity of philosophical reflection on human being is shown. The leading approach to the study of this problem is the ascent from the abstract to the concrete, which makes it possible to comprehend human being and the phenomena of time, finitude, and corporeality associated with it as phenomena that identify the truly human principle in us and manifest the ontological meaning itself. The dialectical method and hermeneutic analysis of the texts of contemporary researchers considering the problems of the philosophical bases of the human personality in the modern world are also used in this study. The article analyzes the status of the personality in the modern technogenic world, in which the uncontrolled stream of simulations and imitations, which include the human being becoming alienated, puts on the brink not only a person's presence in the world, but the world itself as a "native home" of human life. The analysis shows that the possibility of human self-identification in the world is possible only due to the fact that it forms and preserves the human principle in us and is the manifestation of its being. The special role of conscious, sane and responsible action in this process is shown.
\end{abstract}

\section{Introduction}

Turning to the problem of philosophical foundations of personal human selfdetermination in the technogenic civilization is conditioned by the fact that we live in such a cogitative and cultural atmosphere, which plunges us into the world of various mediations, popular symbols and stereotypes, depriving us of the opportunity to truly think and be, thus distancing the man from himself. Today, there are many factors that are slowly destroying our world and creating all sorts of dangers to human physical existence. The studies by Popescu Dan, MacKenzie D., Helmut Nyborg [1,2] and John Smart [3] are devoted to this topic. Scenarios of our planet's death were reflected in the articles by Michael Rampino [4].

However, the problems threatening the modern civilization also entail global changes in culture, touching upon and reshaping the spiritual life of the modern man. This theme is partly

\footnotetext{
* Corresponding author: ttorubarova@rambler.ru
} 
addressed in a study by S. Hofhuis [5]. Thus, the key task for modern man is to oppose the technogenic, informational influences, which negatively affect personal self-determination. In this regard, Nurten Gokalp notes how "it is important to teach people how to use information in the form of original synthesis". Therefore, the goal of education, according to the Turkish researcher, is "to provide people with appropriate conditions for maintaining personal integrity" [6].

That is why, in modern social and cultural circumstances, the approaches to the studying of man, to the understanding of personal self-determination in a situation of complexity and uncertainty of the position of our contemporary in information interaction with the world are changing.

In the study of human problems in the modern world a group of researchers F. Fang, V. Shei, M. Selart suggest using the concept of "cultural intelligence", which was introduced in 2002 and has attracted serious attention of scientists. According to the authors, the development of this type of thinking will contribute to effective human activity in modern social and cultural conditions [7].

The research analysis above shows that the metaphysical problems of the human being are not currently given due attention, as many of the authors mentioned above in general touch upon globalization and related cultural changes, where the emphasis is on understanding the conditions of human life in the world. Therefore, the interest of scientists is concentrated more on resolving particular psychological problems or features of personality development. The topic of philosophical foundations of personal human selfdetermination in a technogenic civilization has not been the subject of special consideration.

Philosophical reflection on the human personality presupposes a special grammar of language combined with the use of abstractions that eliminate any directly empirically perceived base. The clarity of a person's understanding of his or her own being is achieved by overcoming our inclusion in a natural, self-evident reality of presence. We live in such a cogitative and cultural atmosphere, which plunges us into the world of various mediations, popular symbols and stereotypes, depriving us of the opportunity to truly think and be, thus distancing the man from himself. The question of man's understanding of his own being has always been a vital question in the research search for leading representatives of world philosophical thought, preserving to this day the key importance for the Russian philosophical tradition. Thus, in their work, G. E. Alyaev, T. N. Rezvykh, which is dedicated to S. L. Frank, prove that all his life the philosopher returned to reflection on this topic. For him this question was not a theoretical one, but a question of life itself [8]. A man cannot distance himself from the daily life that surrounds him, but he is able to "reborn" in himself and for himself, to express his own essence in "the desire to be human", to regain himself as an "Ego". The need for self-identity is the third (after physiological and social security needs) basic need of the individual. These ultimate meanings, being the vital task of man, put his presence on the verge of being itself. Human existence testifies to our rootedness in being; it has a co-existential character. To feel oneself existing is to be aware of one's own involvement in being as the source of inner transformation. To stand "at the limit", to be born anew each time, to overcome ourselves constantly - this kind of apophaticism turns us into truly human element, being an integral element of human experience. The human destiny lies precisely in this negative ontology. In philosophy, man "is" only in the light of the great Nothing. Man is something that is in a state of constant renewal, this is a human being who, with his own efforts, manages to place himself, his thought, his morality, his desires in some strong magnetic field, coupled with the ultimate forces. It is an event of a formal character, which gives man the opportunity to be such, to recreate himself in his true being, freedom and existence. We say that it is important for the human being to always be in form, that is, to recognize himself in his thoughts and actions, to reach the very identity that will identify in 
us the very human origin, the possibility to be and remain human in any situation. And this is only possible through a form that involves us in it and transforms us.

Formation is something that we must always strive for and follow relentlessly. To gather ourselves in our image that corresponds to our human essence, rather than to dissipate and lose it, is one of the most important human vocations. It is not without reason that the Greeks grasped the possibility of true thinking as $\lambda$ ófos, remembering a single world in which only harmonious human existence is possible. Unfortunately, nowadays, we are losing this key meaning in many respects and in the most essential in relation to all the existing called the world. And this is fundamental for understanding whether the human essence in these conditions of being has the possibility for its own development? The attitude to being expressed in thought crystallizes in the essence of human being, that is in man himself. Both in terms of being and understanding, the key phenomena of human being are connected and interact with each other. Man's understanding of himself derives from this kind of intertwining and unity. The origin of being is always one whole and is a priori the principle of any possible apartness. Therefore, one should not counterpose the individual and the society. Each individual is already initially determined by the structure of coexistence manifesting itself in separate phenomena. We alienate ourselves from our own being, trying to realize it on the level of material substances. The understanding of being, to which we ourselves belong, precedes any terminological, conceptual certainty of anything whatsoever. A human being thinks this world and what happens in it not from a distance and not as something alien, but using the phenomena of his being, i.e. the existence of the understanding. This is what Arendt says, pointing out that thinking is the way we people take root, take our place in the world. R.V. Gulyaev reveals this idea in his work [9], but from an ethical point of view.

In this regard, it is important to realize that our understanding of being already implies being as such. We are present, experienced, complicit in it, forming some existential experience of living life. Each person carries out this kind of complicity in the perspective of his or her own attitude to everything that happens, so to speak, from his or her being and in the area of social relations. It is important to see the human being and related phenomena as truly human phenomena, to recognize the ontological meaning contained in them.

The purpose of this article is to analyze philosophical foundations of self-identification of human being in the modern world.

\section{Materials and methods}

The methodological basis of this research is the method of ascent from the abstract to the concrete, allowing to reveal the problem of human being self-identification through the explication of the essence of human being, through the modus operandi of human existence. The methods of the structural and functional analysis were used to analyze self-identification as a modus operandi of self-determination with the being structure of the individual. In studying the philosophical foundations of human being self-determination, the principles of the systemic approach were used. On the basis of the dialectical method, self-identification as an ontological property of modern human life activity and forms of human self-alienation in the modern world were conceptualized.

\section{Relevance}

The crisis of human self-identity has declared itself most acutely as one of the fundamental problems of the modern society. The question is about the man's preservation of his own "I", which has the meaning of true humanity, becoming people as people. "If in the most general 
plan to raise the question about the essence of globalization, the basic meaning will be the recognition of the principle of convergence different forms, structures and meanings of development of individual state, ethnic, social and personal entities in the modern world", writes Sahakyan A. G. [10]. In the conditions of the controversial modern world, generated by the peculiarities of technological development of modern civilization, the preservation of the basic human identity becomes the most important task. The "I" of the individual human personality becomes the leading trajectory of the philosophizing dominant, which has outlined a new paradigm limit. And as a consequence, there is the responsibility of man for his own essence. Reflection on the context of one's being sets the scale and problem field for the self-determination of the modern man, in terms of constitution of his independence. And this context must now be defined not only and not so much by technical rationality, but first of all by the awareness of the measure and the content of the sane and responsible action, the boundaries of his personal freedom. T.G. Chernova reflects on the key essence of freedom, which gives us responsibility for our own actions in her work [11]. Man's self-consciousness is manifested in his identity. And technoformity in the modern world becomes more and more a manifestation of human identification in the reality constructed by man. That is why the problem of human self-determination is essentially significant and contemporary.

\section{Discussion}

The comprehension of the humanity substance essence is impossible beyond the realization of that metaphysical experience, which lies in the basis of the idea of human existence and its key modi. And I. Kant in his famous "Critiques", first of all, tells and warns us about the boundaries and limits of both cognitive abilities of man and the possibilities and claims of the human mind (pure, scientific mind), calling it to sanity. "But after Kant, one might say, the mentally incompetent mind prevailed. Hegel said that Kant's philosophy was the philosophy of the finite... In the "Phenomenology of Spirit" he constructed the experience of the "mentally incompetent" mind. Based on Hegel, Marx brought to the foreground the domination of the instrumental mind, which finds its own refuge in the so-called philosophy of life. The main condition of life itself is instrumentality, usefulness, and productivity. And the definition of this condition depends on how life itself, above all, human life, is defined in its own essence, whether it is defined by history, which is now more fundamental than nature, or by society, which now depends on political and economic relations, or by the will to superhuman power, which requires constant reassessment of values". This question is analyzed in more detail in T.V. Torubarova's article "F. Nietzsche on the will to power and search for new values" [12].

In this regard, it is important to clarify the following.

Man is finite because of his nature, but finitude is not a negative characteristic of a human being. It constitutes the existential structure of the human being and is its evidence. The human must be understood from itself and through itself and cannot be measured by the measure other than its own. In other words, our reflections on the human being are always connected with time, history, mind, corporality, with everything that constitutes the essence of our nature. And no matter how much we try to orient our mind towards overcoming the borders of our own finitude (virtual reality), be it any sphere of our activity, we should understand that such overcoming always turns into destruction of the human world, as long as we are called to live precisely in it. It is more important, as Aristotle said, to preserve the only cosmos, which we can call the human world, to listen and correspond to it, because the harmony of the world and human existence are interdependent. Therefore, our thinking should have not anger, envy, thirst for profit and power, but the spirit of creation, love, unity and responsibility as its source. 
If the nature of our thinking is in many ways, at least in general, consonant with the nature of all that surrounds us, then it is important to have the possibility of intelligible expression of the nature of such surroundings, that is, its continuous poetization is required. When it is not clear what exactly we are going to say, then we stormily express only our feelings and claims, that is, we just cry out. And the cry is a sound preamble to aggression and bloodshed. "Do not seek the truth where there is shouting," said Leonardo. Man is deprived of the opportunity to reflect if the world around him is in confusion. Confusion blinds, obscures the mind, forces one to act furiously and mechanically. The confused person is plunged almost unreservedly into a biopsychic reality, in which the person is no longer capable of meaningful thoughtfulness and sensitivity. J. Ortega y Gasset notices that in the life of monkeys there is "one absolutely stunning detail": monkeys are constantly on guard, in constant anxiety relentlessly look and listen to what is happening around them, as if afraid that they are always threatened by danger, which should be responded to by flight or bite, that is, by an instant muscle reflex. The environment causes them to be constantly afraid and at the same time contains constant temptations against which they cannot resist, i.e. they are powerless, just like in the face of the feeling of fear. And the man who is absorbed in all that is going on around him, doomed to constant anxiety and being in a state of frenzy, is not able to return to himself, so he is constantly out of himself. He is not able to recognize the world of his own soul, that is, he loses the ability to perceive himself as he is. H. Ortega-i-Gasset reveals the problem of human existence in the philosophy of H. Ortega-i-Gasset in his study, A.V. Shumskaya, concluding that "a man who does not correspond to himself loses his authenticity" [13].

He can no longer recognize himself authentically. Every distinction between good and evil disappears. What is good for man is only his own existence in the world around him. A personality dissolves in its surroundings, is does not come to itself, it does not have itself. It is a question of one's own significance in actual recognition, that is, in life's relationships with the world around. It is a complete immersion in its surroundings, accompanied by the loss of self. It is a state of forgetfulness. In this position, man is deprived of the possibility to reflect, self-absorb and meaningfully heed all that exists. At present, "philosophical thought at the present stage, reflecting the most important forms of alienation existing in society, focuses on those in which a person feels deprived of his most important essential characteristics", writes Yevloeva F. R. [14]. The above mentioned circumstances lead to the loss of the need for self-identity, which was mentioned by E. Fromm. It is rooted in human nature, and without which a person cannot feel healthy.

The inner world of man is his self, permeated with the essence of meaning. Thoughts are deprived of a certain location both in a corporeal man and in the world around him. The animal is either constrained by what is happening or falls asleep. Man seeks to be at home everywhere, and this aspiration expresses the very essence of philosophy. Concentration of thought protects man from the danger of dissolution in what is happening, from the danger of dissipation of his presence in the world. After all, it is always natural to disperse into the external, to be absorbed by a continuous series of external impressions. It is not true that thinking was given to man once and for all as a certain ability that is constantly at his disposal. Thinking is not an element as natural to man as, for example, air. The dramatism inherent in the condition of human existence is that "of all creatures in the universe, man is the only one who can never be sure that he is human", a true human, capable of thinking in the most real way. It is clear that the human presence is always mine in one way or another, but mine is not always occupied by me, just as I am no less often occupied by not mine. More often and above all we act and think "like people", because "people" are present in us and through us instead of us. The human being is actualized not in one of his abilities, but in his being of understanding-presence-in-the-world and keeper of it, i.e. world, truth. The memory that the earthly presence of each of us is finite forces the human being to bind the plan of its 
fulfillment to one or another period of time. The time of a human being and the time of the world he contains is measured by the measure of fulfillment. And the world itself, the diversity of historical situations is each time interpreted within the framework of selfunderstanding defined by tradition. "But Heidegger, in asserting the finite nature of true temporality, interprets consciousness itself as a certain way of being. He discovers this way of being in nothing else, as in the ability to understand one's own being", writes Ishchenko N. I. [15]. And the most difficult thing for a human being is to fulfill himself in the essence of true thinking, not only since thinking has not descended on a human being by itself, but even, on the contrary, having traveled a difficult and often painful historical path, a human being is still in many ways an unreasonable being. And a person easily loses the very thing that has been achieved or once existed precisely in the sphere of thinking. To be a thinking individual means always having the possibility to stop being that individual. Man's being is always problematic; each of us can lose his inherent self at any moment, because the individuality of each of us, the personality of each of us, "is never fulfilled to the end," and there is "a certain exciting utopia, a certain secret myth that each of us keeps at the very depth

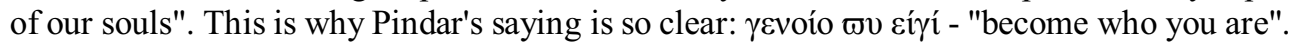

All that was once acquired by man is unreliable, can easily be lost, so it requires a continuous effort in order to keep it. To "be" a man means to remain in a constant effort, the courage to "be"; the overcoming, without which he is impossible, baseless in his essence. In the modern world, spinning in an unbridled flow of endless simulations and imitations, the meeting with one's self becomes a truly existential task. The human being and what makes our self-identification possible send us to the domain of love, duty, conscience, responsibility at last; that is, to everything that forms in us the human origin and is the manifestation of its being. We are now signing a written acknowledgment of our own exhaustiveness, testifying to the splitting of the human being forced to imitate himself. Everyday reality forms a new "ethos", which dictates its "rules of the game", immerses us in such a horizon of life activity, in which the adaptive possibilities of man change in connection with adaptation to the conditions and requirements of another sphere of being, which in essence simulates human existence itself. Reality becomes a simulacrum, a played spectacle. Reality is overshadowed by hyper-reality and can only exist on the borderline between play and reality, while "real" and "imitation" are indistinguishable or even swap places. The true, in order to exist and exert influence, must also imitate itself, including imitating its own authenticity. This reality is woven from fictions, and conversely, these fictions have become the only reality. Man becomes a simulacrum and cannot make notice of whether he really exists, or whether some forces exist through him that form him for life. The problem of existence is the problem of overcoming the seeming life that constantly pursues us.

The history tells us about countless u-turns, decay and rebirth. But probably, such turns are possible in which man will completely lose the human features, that is, his own image. When the Greeks discovered such a strange thing as thinking, they began to comprehend this kind of unexpected gift through $\lambda$ ó $\gamma$ os as a gathering into one whole of everything revealed by itself. For them thinking is the greatest thanksgiving, so the deity of Aristotle thinks only about thinking.

The essence of a human being is always danger and risk, which can lead to such a frantic confusion, in which the person may lose the ability to return to himself. Our time is a time of demagogues sowing confusion everywhere, driving people into crowds and thus depriving them of the opportunity to be alone with themselves. They stir up passions and achieve the result that people facing the horrors of life get drawn in a frenzy. Such a spectacle is always represented by epochs that deify pure activity. And then the atmosphere of crime condenses, human life loses its meaning, and the world is ruled by violence and robbery. If a mighty doer appears on the horizon, then there comes a time for reckless actions. Until recently, maybe this retrospective view of the human problem was enough. "However, today in connection 
with NBIC-technologies and the question about the prospects of the post-human future, the problem of human nature has acquired a moral and ethical, value dimension", - indicate in their work I.V. Chernikova, V.V. Sherenkova. And in this sense, the warning of Hans Jonas sounds relevant, reasoning about the human responsibility for his image in the following way: "only the predicted deformation of man helps us to come to the concept of man, which should be protected from it, and we need a threat to the human image, and quite a specific threat, so that, afraid of it, to secure a genuine human image" [16].

Historical remembering and reflection of the present state of affairs, i.e. a thought aware of comprehending of the present, are not just two ways of comprehending the idea of philosophy as such, but two essential elements of precisely philosophical thinking. True thought has a reciprocal character, it always returns to its origins, acquiring the necessary energy, the tension that allows it to rethink and rename everything. It is a way of thinking that is capable of realizing, that is of being sane and, therefore, responsible, participating in the unified and the whole. Involvement in the whole characterizes the true way of being presence of man, of him finding his "I", of being aware of his responsibility. A conscious, sane and responsible action forms a human being in us. Human being is a co-existence that presupposes participation in the world as a whole, in its connections and relations. And as such, it manifests the existence of the human personality, which identifies itself through a response, responsive attention to everything that happens in the existence of the unified world. Thus, the integral individual "I", fulfilled in this kind of response, reaches the unity of the personality, its correspondence and its compatibility with all existing things as such.

The boundaries of freedom and responsibility are now narrowing; the boundaries of the personality are being blurred. Moreover, the sanity of the human being dissolves in the dissipating "I". The diversity of human social roles sometimes provokes a situation of alienation, when the individual does not reach himself or herself, i.e., is unable to identify himself or herself. The question arises: what is our true identity, in a world of endless $\tau \varepsilon \dot{\chi} \chi \eta$ manipulations, including corporality, and does it not lead to inhuman forms?

\section{Conclusion}

In the modern technogenic world a man loses himself, identifying his own corporality with various mechanisms and believing that the technical environment is a "natural" womb of his presence. The nature surrounding the man more and more quickly turns into a civilization with an artificial structure: either directly (it is transformed, technified), or indirectly (it enters intact into the intricacies of intentions of the goals existing in the human society). We plunge into a virtual space where the difference between here and there, mediated by computer terminals and video monitors, loses all meaning.

We are approaching the limit of our own independence in the world around us, finding ourselves everywhere in the face of our deeds in the circle of artificially created environment; we do not meet ourselves anywhere. In other words, the human deeds detached from man and nature become an independent practical value, which differs from the original natural consistent pattern and from the original human purpose. It is the phenomenon of alienation, the so-called "absent presence" of man in the modern world, that turns this world into a human problem and brings to the foreground the question: "what does it mean to be human?

In the human being and human activity, a world that opens up new dimensions of existence and time comes to the forefront. The question of what man is becoming inevitable. The content of this question crosses the boundaries of history and includes the question of what the world is? For the discrepancy between the human being and the world creates a limited form of their relationship. Man, adapted to the virtual environment, is increasingly alienating himself from his own essence, which is defined by human nature. He increasingly identifies himself in a techno-form way. Modern civilization is more characterized by 
technomorphism, which is expressed in attempts to reproduce the image of the living, even to replace it. Man rushes to the other extreme, obeying the technoform identification. Identity testifies to man reaching a certain level of self-consciousness, self-consciousness of one's own "I". Such level is associated with the freedom and responsibility of a particular doer. A person's self-affirmation is produced by his freedom. But it is in this freedom that his alienation is also rooted. This dialectic is an internal contradiction of human freedom. On the one hand, the technical environment of the modern man is thought of as one of the highest forms of his self-affirmation, the fulfillment of freedom; on the other hand, the situation of a person included in such an environment turns into technomorphism, his otherness, in essence, eliminating the inherent human origin. That is why it is important for man, in maintaining his identity, the proper human essence, to consider personal responsibility as the principle of his own being, in the already mentioned sense, preserving the world as the condition of presence and self-preservation in that harmony with all the existing beings, in which only man as such is possible.

Thus, the self-determination of man in the world is possible only in the perspective of preserving the foundations of human being, the awareness of man of his own limits and possibilities, beyond which, as I. Kant would say, the human mind should not go. Awareness of responsibility for one's decisions and actions, for one's choice becomes the principle of survival of man as a meaning-making link in the universal chain of being. The responsibility for the integrity of being, for the harmony of the world allows comprehending the predestination of man and his self-value in a cosmic way.

\section{References}

1. Dan Popescu, Procedia Economics and Finance 8, 570 - 575 (2014) doi: 10.1016/S22125671(14)00130-0

2. H. Nyborg, Personality and Individual Differences 53, 118-125 (2012) DOI: 10.1016 / j.paid.2011.02.031

3. J.M. Smart, Acta Astronautica 78, 55-68 (2012) DOI: 10.1016/j.actaastro.2011.11.006

4. M.R. Rampino, Supereruptions as a Threat to Civilizations on Earth-like Planets Icarus 156, 562-569 (2002) DOI:10.1006/icar.2001.6808

5. M. Boudry, S. Hofhuis, Cognitive Systems Research 52, 155-167 (2018) DOI: 10.1016 / j.cogsys.2018.06.010

6. N. Gokalp, Procedia - Social and Behavioral Sciences 47, 477-479 (2012) DOI: 10.1016 / j.sbspro.2012.06.683

7. F. Fang, V. Schei, M. Selart International Journal of Intercultural Relations 66, 148-171 (2018) DOI: 10.1016 / j.ijintrel.2018.04.002

8. G.E. Alyaev, T.N. Rezvikh, Russian-Byzantine bulletin 1, 82-112 (2018) DOI: 10.24411/ 2588-0276-2018-10006.

9. R.V. Gulyaev, Vestnik of Tomsk State University. Political science 37, 16-29 (2017) DOI: $10.17223 / 1998863 \mathrm{X} / 37 / 2$

10. A.G. Sahakyan, Scientific and technical bulletins of St. Petersburg State Pedagogical University. Humanities and social sciences 8(4), 88-95 (2017) DOI: 10.18721/JHSS.8409.

11. T.G. Chernova, Vestnik of Perm University. Sociology 1, 45-52 (2018) DOI: 10.17072/2078-7898/2018-1-45-52.

12. T.V. Torubarova, Vestnik of Vyatka State University 3, 4-12 (2018) DOI: 10.25730/VSU.7606.18.017. 
13. Shumskoy A.V. Vestnik of Perm University. Sociology 2, 194-203 (2019) DOI: 10.17072/2078 7898/20192194203.

14. F.R. Yevloeva, Vestnik of Buryat State University. Philosophy 2, 74-82 (2019) DOI: 10.18101/1994-0866-2019-2-74-82.

15. N.I. Ishchenko, Scientific yearbook of In-ta philosophical and law Ural, Russia. Nauk 18(3), 27-46 (2018) DOI 10.17506/ryipl.2016.18.3.2746.

16. I.V. Chernikova, V.V. Sherenkova, Vestnik of Tomsk State University 399, 24-27 (2015) DOI: 10.17223/15617793/399/5. 